\section{Patient perceived quality of nursing care in hemodialysis: A meta-synthesis}

\author{
Abbas Balouchi, ${ }^{1}$ Abbas Ebadi, ${ }^{2,3}$ \\ Soroor Parvizy, ${ }^{4}$ Hamid Sharif Nia \\ ${ }^{1}$ Student Research Committee, Faculty \\ of Nursing and Midwifery, Iran \\ University of Medical Sciences, Tehran; \\ ${ }^{2}$ Behavioral Sciences Research Center, \\ Life style institute, Baqiyatallah \\ University of Medical Sciences, Tehran; \\ ${ }^{3}$ Nursing Faculty, Baqiyatallah \\ University of Medical Sciences, Tehran; \\ ${ }^{4}$ Department of Nursing, Iran University \\ of Medical Sciences; ${ }^{5}$ School of Nursing \\ and Midwifery Amol, Mazandaran \\ University of Medical Sciences, Sari, \\ Iran
}

\begin{abstract}
This study was done with the purpose of clarifying the concept of patient perceived quality of nursing care in hemodialysis. In this meta-synthesis study, qualitative studies was searched in the four interntional databases from January 1st, 2000 to December 30th, 2019. The keywords used were: nursing care quality, and hemodialysis. Studies which had been done with the purpose of understanding the patient perceived quality of nursing care concept aomg hemodialysis patients were included. Two researchers were evaluate the quality of included studies separately using JBI tool, required information were extracted using the designed table. The main themes in the structure dimension include Sufficient Human resource, quality of equipment, financial support from patient and quality of the patient care environment. Process dimension consisted of continuous monitoring of the syndromes, effective patient education, efficient care, effective therapeutic relationship, and patient's empowerment and participation in the process, and in the outcome dimension included high dialysis adequecy, patient burnout reduction, and increased patient satisfaction from services. The results of the study indicated a comprehensive, deep and interactive dimensions about the concept of nursing quality of care.
\end{abstract}

\section{Introduction}

Today, chronic diseases including chronic kidney disease (CKD) consider as one of the most important health challenges.
The prevalence of CKD in the world and Iran is $13.4 \%{ }^{1}$ and $15.6 \%{ }^{2}$ respectively. Of the 500 million people with CKD, about 80 percent of them live in less developed countries. ${ }^{3}$ Asia, which have 60 percent of the world's population, has the highest prevalence statistics of infected with CKD. ${ }^{4}$ In over $90 \%$ of CKD patients, hemodialysis is the only treatment option. ${ }^{5}$ In Iran, the number of patients with CKD is about 84,000 , of which more than $82,000(89 \%)$ are undergoing hemodialysis. ${ }^{6}$ Using hemodialysis while saving millions of lives, is accompanied with various physical complications (vascular access complications, cardiac complications, gastrointestinal bleeding, cancer, bones metabolism disorder, ineffective dialysis adequecy, skin problems, anemia, loss of appetite, muscle cramps and psychological complications (sleep disorder, depression, fatigue, reduce the quality of life and anxiety). ${ }^{7}$ On the other hand, better care in hemodialysis patients causes improving therapeutic indicators in patients. $^{8}$

Health policy-makers around the world face to challenge of quality of cares provided for chronic diseases, because more than $50 \%$ of the burden of diseases belongs to chronic non-contagious diseases such as CKD. ${ }^{9}$ Nursing care quality has also been changed in to a central principle in the health cares of patients with CKD. Various definitions have been presented by organizations and experts about the concept of care quality. According to the definition of American Medicine Institute, "Quality of care (or care quality) is a degree of providing health cares to individuals and populations that maximizes desired health outcomes and is consistent with current professional knowledge." 10 Quality of care is defined by the World Health Organization as: to what extent services provided to individuals and patients would reach them to mentioned health outcomes. That to reach this goal, the cares must be safe, effective, efficient, timely, fair and people-oriented. ${ }^{11}$ Experts also provided different definitions on quality of care. Donabedian considers the quality of care as performing all necessary measures to help the patient which reflects the present values and goals of the individual and the care system. ${ }^{12}$ Having agreement on a correct and clear definition of the nursing care quality can promote the health, support, and correct education of patients. ${ }^{13}$ Today, the perceived care quality from the perspective of the patient is raised as one of the main components of care in the health system. ${ }^{14}$ Paying attention to the patient's perspective leads to increase quality of life, safety level, private satisfaction associated with disease progression, and
Correspondence: Soroor Parvizy, Full Professor, Department of Pediatric Nursing, School of Nursing and Midwifery, Iran University of Medical Sciences (IUMS) Rashid Yasmi st, Valiasr blvd, Tehran, Iran.

E.mail: jahant1992@gmail.com

Key words: Patient satisfaction; syndrome; renal dialysis; nurse-patient relations; patient care; workforce.

Acknowledgments: This study is part of a Ph.D. thesis in Nursing. I would like to thank the Research Assistant of the Faculty of Nursing and Midwifery.

Contributions: All the authors contributed equally.

Conflict of interest: The authors declare no conflict of interest

Funding: Iran University of Medical Sciences

Ethics approval and consent to participate This study was approved by the Ethics Committee of Iran university of Medical Sciences (ethic code: IR.IUMS.REC 1398.673)

Consent for publication: Not aplicable.

Availability of data and materials: The datasets used and/or analyzed during the current study are available from the corresponding author on reasonable request.

Received for publication: 21 August 2020.

Revision received: 10 September 2020.

Accepted for publication: 11 September 2020

This work is licensed under a Creative Commons Attribution 4.0 License (by-nc 4.0).

(C) Copyright: the Author(s), 2020

Licensee PAGEPress, Italy

Healthcare in Low-resource Settings 2020; 8:9320 doi:10.4081/hls.2021.9320

knowledge. The outcome for the system can also be reduction of new beds rate (readmission), optimal use of resources, and providing more service with more cost-effective. ${ }^{15}$ On the other hand, various studies show a positive relationship between attending to patients' perspectives and increasing the nursing care quality of patients and increasing their satisfaction. ${ }^{16}$ Although the concept of nursing care quality has been clarified to some extent from the perspective of organizations $^{11}$ and experts ${ }^{17}$ and nurses, ${ }^{18,19}$ the reviewing literatures indicate that this concept has been less evaluated by patients under hemodialysis who have different conditions in terms of complications, symptoms, severity of illness, concomitant 
illnesses, and required care and have main contribution in the care chain. It is also very essential to pay attention to patients 'opinions through understanding the various psychological, emotional, physical, social dimensions of patients and, as a result, a deep understanding of patients' needs for doing holistic care. This study was done with the aim of clarifying the concept of patient perceived quality of nursing care from the perspective of patients undergoing hemodialysis based on existing studies.

\section{Materials and Methods}

\section{Design and eligibility criteria}

In this meta-synthesis study, qualitative studies related to the experiences of hemodialysis patients on the quality of nursing care was evaluated using a systematic review approach. Inclusion criteria in this study include: known patients undergoing hemodialysis who had passed at least 6 months from their first dialysis session. The included studies were qualitative and were published in English. Exclusion criteria: review studies, quantitative studies (crosssectional, RCT, case control, case report, case series, and letter to editor) were excluded.

\section{Search strategy}

Four international electronic databases inlclude: web of sciecne, PubMed, Scopus and Embase searched from January 1st, 2000 to 30 December 30th, 2019. The articles were searched in three stages. First, a targeted and centered search in PubMed and Scopus was conducted with the purpose of finding the most relevant articles using related keywords. Then, a comprehensive search was performed in all selected databases. The search strategy was written by two researchers (AB, AE) with the advice of a librarian expert. In the third step after searching the databases, the sources of related articles were also evaluated to find more articles.

\section{Screening the studies}

The studies searched in the various databases were included Indenot. Duplicate studies were initially removed. In this way that firstly duplicate studies were evaluated based on title and duplicate studies were excluded, then the remaining studies were reviewed and excluded based on their abstract. In the final step, the full-text version of the articles was evaluated based on the inclination criteria and the irrelevant items were excluded. Screening the studies were performed separately by two researchers (AB, SP). The disagreement between the two persons was discussed and resolved by a third party.

\section{Evaluation of studies quality and data extraction}

The JBI tool for qualitative studies was used to evaluate the quality of the included studies. ${ }^{20}$ This tool was consisted of 10 items which assessed the methodology and how to report qualitative studies. Two researchers individually performed the evaluation of the studies quality. Disagreement cases between two persons were being resolved by a third party. Data extraction was performed using data extraction tables in Excel and Word. The extracted data included: article number, author, year of publication, country, title, purpose of study, number of participants, method of work, data collection, analysis method and main results and themes.

\section{Data analysis}

Thematic approach of analysis was used for data analysis. In this approach, the codes were systematically classified and the descriptive and analytical themes were clarified and analyzed. First, the results of the included studies were studied line-by-line, and then the cases related to the purpose of the study were clarified as free codes and in the following similar and different codes were identified through constant comparison. Similar codes were then named as descriptive themes, and in the final step, the themes were identified analytically and abstractly, and together were formed the definition of concept of perceived nursing care quality from the perspective of the patient. $^{21}$

\section{Results}

\section{Select the studies}

The 4,386 searched records in various databases have been included in Indenot. 3474 non-duplicated studies were evaluated on the basis of title and abstract, of which 24 records entered the final stage. Out of 24 included studies, 6 studies were included in meta-synthetic and 18 studies were excluded [review $(n=2)$, non-english $(n=10)$, no quality $(\mathrm{n}=1)$, no full text $(\mathrm{n}=5)]$ (Figure 1$)$.

\section{Characteristics of included studies}

Out of the six included studies, 4 studies were conducted using the content analysis approach and 2 studies were conducted through Focus Group on 189 participants. Data were collected through semi-structured interviews in all studies. In most stud-

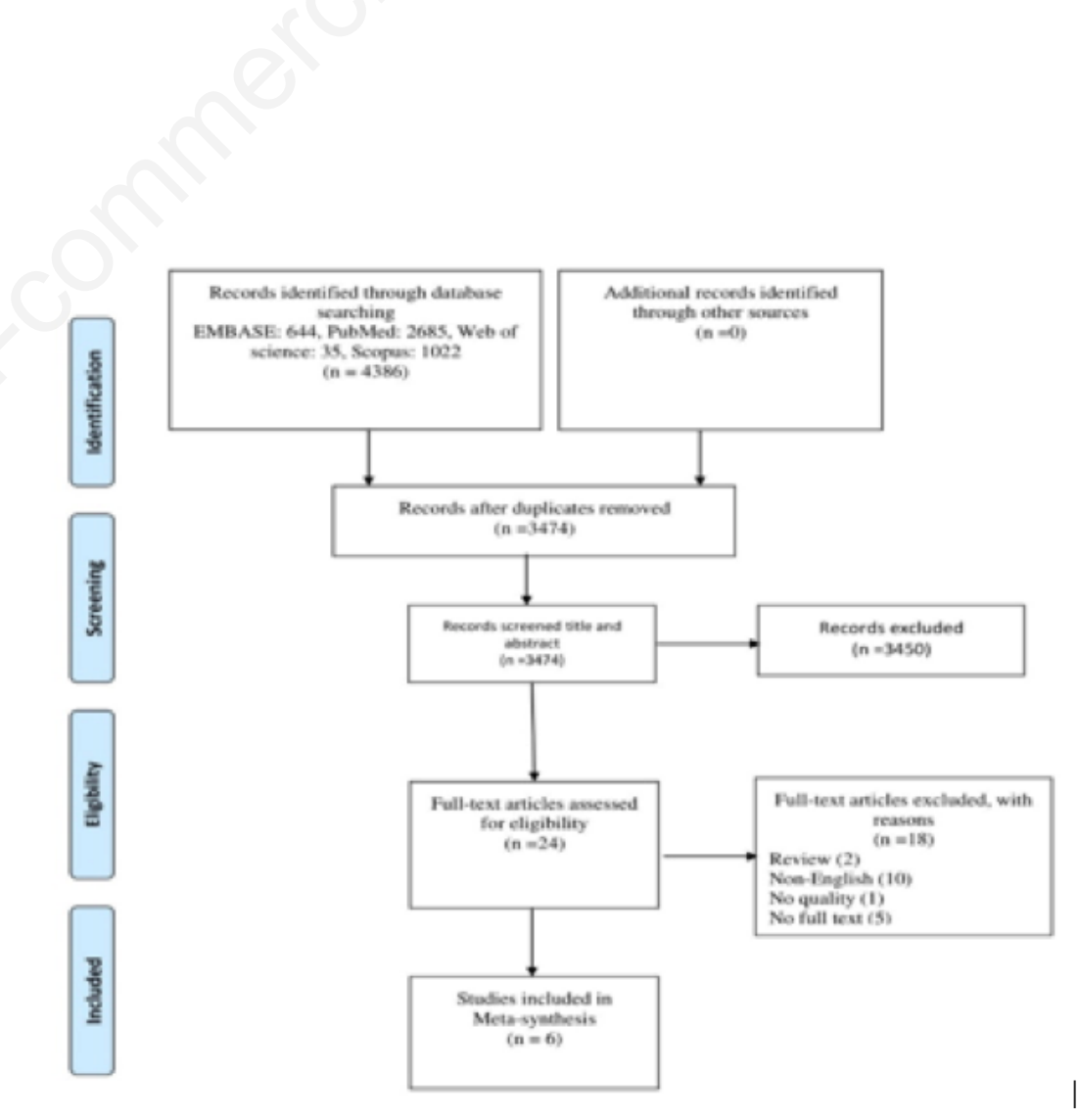

Figure 1. Studies selection process. 
ies $(n=5)$, data were analyzed using content analysis method (Table 1).

\section{Main results}

The most well-known model used to classify care quality components is the Donabedian model, which classifies the quality of cares provided into three parts: structure, process, and outcome (25). The perceived nursing care quality from the patients' perspective was consisted of three main themes: structure, process, and outcome (Figure 2).

\section{The structure of perceived quality of nursing care}

Proper structure of perceived nursing care quality from the perspective of patients was composed of four different sub-themes including: sufficient suman resource, quali- ty of equipments, financial support from patient and adequacy of the patient care environment.

\section{Sufficient human resource}

Sufficient Human resource is one of the main components of quality care from the patients' point of view. Sufficient Human resource means appropriate number of nurse, kidney specialist, nutritionist, social

Table 1. Characteristics of the studies

\begin{tabular}{|c|c|c|c|c|c|c|c|c|}
\hline ID & $\begin{array}{l}\text { Author } \\
\text { (year) }\end{array}$ & Country & $\begin{array}{l}\text { Purpose } \\
\text { of study }\end{array}$ & $\begin{array}{l}\text { Study } \\
\text { design }\end{array}$ & $\begin{array}{l}\text { Sample } \\
\text { characteristics } \\
\text { 1.participants } \\
\text { 2.population } \\
\text { 3.age } \\
\text { 4.gender (female/male) }\end{array}$ & $\begin{array}{l}\text { Data } \\
\text { collection }\end{array}$ & $\begin{array}{l}\text { Data } \\
\text { analysis }\end{array}$ & $\begin{array}{l}\text { Main } \\
\text { results }\end{array}$ \\
\hline 1 & $\begin{array}{l}\text { Rubin, H. R. } \\
(1997) \\
24\end{array}$ & USA & $\begin{array}{l}\text { We conducted } \\
\text { a study to } \\
\text { identify salient } \\
\text { attributes of } \\
\text { dialysis care } \\
\text { and to rank the } \\
\text { importance } \\
\text { of these } \\
\text { attributes from the } \\
\text { perspective of dialysis } \\
\text { patients. }\end{array}$ & $\begin{array}{l}\text { Focus } \\
\text { group }\end{array}$ & $\begin{array}{l}1.86 \\
\text { 2.patients, } \\
\text { nephrologists } \\
3.56 .1 \\
4.40 / 46\end{array}$ & $\begin{array}{l}\text { Focus group } \\
\text { with interview }\end{array}$ & $\begin{array}{l}\text { Content } \\
\text { analysis }\end{array}$ & $\begin{array}{l}\checkmark \text { Sufficient human resource } \\
\checkmark \text { Quality of equipment used } \\
\checkmark \text { Quality of patient care environment } \\
\checkmark \text { Effective patient education } \\
\checkmark \text { Financial ability and insurance support }\end{array}$ \\
\hline 2 & $\begin{array}{l}\text { Wuerth, } \\
\text { D. B.(2000) } \\
25\end{array}$ & USA & $\begin{array}{l}\text { Patient Assessment } \\
\text { of Quality of Care in } \\
\text { a ChronicPeritoneal } \\
\text { Dialysis Facility }\end{array}$ & $\begin{array}{l}\text { Focus } \\
\text { group }\end{array}$ & $\begin{array}{l}1.30 \\
\text { 2. Patients } \\
3.57 \\
4.13 / 17\end{array}$ & $\begin{array}{l}\text { Structured } \\
\text { interview }\end{array}$ & $\begin{array}{l}\text { Thematic } \\
\text { analysis }\end{array}$ & $\begin{array}{l}\checkmark \text { Efficient care } \\
\checkmark \text { Sufficient human resource } \\
\checkmark \text { Effective patient education } \\
\checkmark \text { Quality of dialysis environment }\end{array}$ \\
\hline 3 & $\begin{array}{l}\text { Rodrigues, } \\
\text { T.A. (2009) } \\
26\end{array}$ & Brazil & $\begin{array}{l}\text { To describe the } \\
\text { representation of } \\
\text { nursing care for } \\
\text { nurses and for } \\
\text { individuals } \\
\text { undergoing } \\
\text { hemodialysis }\end{array}$ & $\begin{array}{l}\text { Qualitative } \\
\text { study-content } \\
\text { analysis }\end{array}$ & $\begin{array}{l}1.12(6 \mathrm{n} .6 \mathrm{p}) \\
\text { 2. Patients, } \\
\text { nurses } \\
3.62 \\
4.15 / 8\end{array}$ & $\begin{array}{l}\text { Semi-structure } \\
\text { interviews }\end{array}$ & $\begin{array}{l}\text { Content } \\
\text { analysis }\end{array}$ & $\begin{array}{l}\checkmark \text { Therapeutic communication } \\
\checkmark \text { Patient participation in treatment } \\
\checkmark \text { Participation in decision making }\end{array}$ \\
\hline 4 & $\begin{array}{l}\text { Nobahar, } \\
\text { M. (2016) } \\
23\end{array}$ & Iran & $\begin{array}{l}\text { "The aim of this } \\
\text { study was to } \\
\text { assess the barriers } \\
\text { and facilitators } \\
\text { of care for } \\
\text { hemodialysis } \\
\text { patients." }\end{array}$ & $\begin{array}{l}\text { Qualitative } \\
\text { study- content } \\
\text { analysis }\end{array}$ & $\begin{array}{l}1.20 \\
\text { 2.patients, } \\
\text { nurses, } \\
\text { physicians, } \\
\text { caregivers } \\
\text { 3.51.37 } \\
\text { 4. None reported }\end{array}$ & $\begin{array}{l}\text { Semi-structured } \\
\text { interviews }\end{array}$ & $\begin{array}{l}\text { Content } \\
\text { analysis }\end{array}$ & $\begin{array}{l}\checkmark \text { Effective communication between } \\
\text { nurses and patients. } \\
\checkmark \text { Sufficient human resource. } \\
\checkmark \text { Correct policy making to support dialysis. } \\
\checkmark \text { Effective and efficient environment. }\end{array}$ \\
\hline 5 & $\begin{array}{l}\text { Nobahar, } \\
\text { M.(2017) } \\
18\end{array}$ & Iran & $\begin{array}{l}\text { "he present } \\
\text { study was } \\
\text { conducted to explore } \\
\text { the experiences } \\
\text { of the } \\
\text { quality of nursing } \\
\text { nurses, caregivers and } \\
\text { care among patients, } \\
\text { physicians in an HD } \\
\text { department in Iran. }\end{array}$ & $\begin{array}{l}\text { Qualitative } \\
\text { study- } \\
\text { content } \\
\text { analysis }\end{array}$ & $\begin{array}{l}1.20 \\
\text { 2. Patients, } \\
\text { nurses, } \\
\text { physicians, } \\
\text { caregivers } \\
3.51 .37 \\
\text { 4.none reported }\end{array}$ & $\begin{array}{l}\text { Semi-structured } \\
\text { interviews }\end{array}$ & $\begin{array}{l}\text { Content } \\
\text { analysis }\end{array}$ & $\begin{array}{l}\checkmark \text { Continuous monitoring of the patient by } \\
\text { the nurse. } \\
\checkmark \text { High dialysis adequacy. } \\
\checkmark \text { Burnout } \\
\checkmark \text { Effective patient education } \\
\checkmark \text { Effective empowerment in doing activities } \\
\checkmark \text { Sufficient human resource. } \\
\checkmark \text { Communicate effectively. } \\
\checkmark \text { Quality of equipment used. } \\
\checkmark \text { Effective and efficient environment. }\end{array}$ \\
\hline 6 & $\begin{array}{l}\text { Hashemi, } \\
\text { M. S. (2018) } \\
22\end{array}$ & Iran & $\begin{array}{l}\text { "Thus this research was } \\
\text { undertaken to study } \\
\text { the needs and } \\
\text { demands of such } \\
\text { patients." }\end{array}$ & $\begin{array}{l}\text { Qualitative } \\
\text { research- } \\
\text { content } \\
\text { analysis }\end{array}$ & $\begin{array}{l}\text { 1.21 } \\
\text { 2. Nurses, } \\
\text { nephrologist, } \\
\text { clinical } \\
\text { psychologists, } \\
\text { social workers. } \\
\text { 3.51.37 } \\
\text { 4.none reported }\end{array}$ & $\begin{array}{l}\text { Semi-structured } \\
\text { interviews }\end{array}$ & $\begin{array}{l}\text { d Content } \\
\text { analysis }\end{array}$ & $\begin{array}{l}\checkmark \text { Effective symptoms management } \\
\checkmark \text { Effective full- support } \\
\checkmark \text { Quality of the nursing services delivery } \\
\checkmark \text { Sufficient human resource } \\
\checkmark \text { Communicate effectively } \\
\checkmark \text { Effective infection control } \\
\checkmark \text { Quality of equipment. }\end{array}$ \\
\hline
\end{tabular}


helper who have the sufficient training knowledge and skill to care of patients undergoing hemodialysis. Also, Sufficient Human resource means professional human power behavior (being accessible and on time). ${ }^{18,22-25}$

"The nurse should have enough information about kidney and electrolytes, because a small error in the selection of filter, blood flow, and UF could lead to the worst electrolytic problem." (Study 4$)^{23}$

\section{Quality of equipment}

The quality of the used equipment is: a sufficient number of different equipment (dialysis machine, dialysis set, etc.) that are new and have a correct performance. ${ }^{18,22,24,25}$

"Whenever a new dialysis machine is brought in, another one breaks down, and who knows when this other one is going to be repaired? There is always a shortage of machines in the department." (Study 5) $)^{18}$

\section{Patient financial support}

Financial ability has always been one of the most important factors in clarifying patients' following rate to diet to achieve nursing care quality. Various studies have shown that patients undergoing dialysis are financially troubled with respect to poor economic backgrounds, losing job in most of the time du to provide medicines, physician visits to control long-term complications of dialysis, and following from diet. ${ }^{22-24}$

"Whenever I visit a physician's office, I have to pay a sum of money. Visits, tests and medicines must be paid for after all. If all the patients were regularly paid for their steady jobs, there would be no problems. But how can you afford the medication and in-dwelling catheters when you are out of a good job". (Study 6)22

\section{Quality of environment care}

The proper environment is one of the key factors in the perceived care quality from the perspective of patients. Suitable environments means physical conditions (appropriate light, temperature, and sound), audiovisual equipment, patient rest room, cleanliness of the ward, comfort and being standard of dialysis bed, maintaining patient privacy, and parking. ${ }^{18,24,25}$

"The beds are too close to each other in the ward, and there is little room between the bed and the machine, and 13-14 patients undergo dialysis at the same time in this tiny space." (Study 5) ${ }^{18}$

\section{The process of perceived quality of nurs- ing care}

The process of perceived nursing care quality from the patients' point of view was consisted of five sub-items: continuous monitoring of syndrome, effective patient education, efficient care, effective therapeutic relationship, and participation, empowering the patient in the care process.

\section{Continuous monitoring of the syndrome}

Continuous monitoring of the physical and psychological state of patients before, during and after dialysis is one of the main duties of the therapeutic team, especially nurses, who spend more time with the patient. Patients undergoing dialysis experience usually high stress due to being attached to the device and hemodynamic

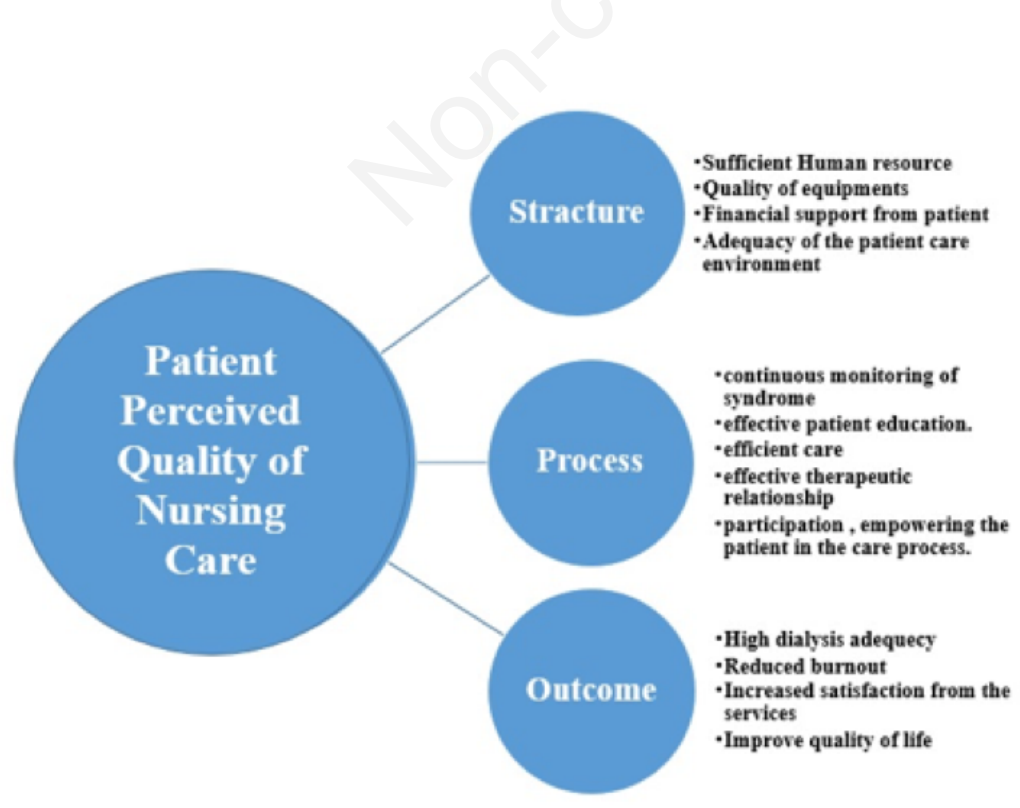

Figure 2. Patients' perceived quality of nursing care concept in hemodialysis patients. changes during dialysis. The most important physical stressors include fatigue, weakness, nausea and vomiting and appetite problems, respiratory complications, and complications during hemodialysis including hypotension, headache, and muscle cramps. Therefore, continuous attention to these patients is needed. ${ }^{18,22}$

"I spend four hours under this dialysis machine, and every second of it is still part of my life. The nurses should be in of everything. My nurse calls on me every $15 \mathrm{~min}$ utes or so and checks my blood pressure." (Study 5) ${ }^{18}$

\section{Effective patient education}

From the patients' point of view, training to the patient effectively, especially immediately after the disease diagnosis and at the beginning of dialysis, have a significant contribution in improving patients' health patterns and improving the nursing care quality. The key components of a correct education to patient from the patients' point of view are the number of educational resources, rich content and patient's problem-related content that are based on the latest medical information, and people who provide this explanation patiently and completely. ${ }^{18,22,24}$

"We begin calcium carbonate therapy with three pills, but the patient takes one every day and may develop bone disease as a result. The patient does not have adequate knowledge about these therapies, although a lot of their problems tend to disappear when you explain everything to them, and then they begin to understand why they have developed spontaneous fracture of the femur, and why their phosphorus levels are so high, and why their hands and feet hurt." (Study 5) ${ }^{18}$

\section{Efficient care}

Efficient care means to provide sufficient competence of dialysis ward to provide services, pay attention to the patient's needs in the ward, atmosphere between human power, and pay attention to patients concerns. ${ }^{25}$

"They are always there if you need them," and "they always listen to my concerns." and "the staff is like a family." (Study 2) $)^{25}$

\section{Effective therapeutic relationship}

Effective therapeutic relationship as an important component of the perceived nursing care quality from perspective of patients undergoing hemodialysis means time spent for communicating with the patients by the treatment team, having intimate, friendly 
and mutually respect relationship so that patients experience the feeling of taking care in the dimensions of physical, emotional, health, and getting well of all members of the dialysis ward. ${ }^{18,22,23,26}$

"Being cared related to health, social, feelings and well-being through the entire clinic: doctors, other patients (my partners), nurses, workers in general." (Study $3)^{26}$

\section{Participation and empowerment in care}

It means performing activities that enable patients to be actively involved in the treatment process and the empowerment process is done for them and ultimately they become independent to do affairs. These activities include timely medication use, observing the hygiene, full-observance of diet, exercise, and weight control. ${ }^{18,26}$

"Being well cared is to recover better and pass well in the hemodialysis, it is having control with the eating, personal hygiene and from the arm and medication. It is eating properly according to the diet, taking medicines on time, follow the schedule and aware with the weight." (Study 3$)^{26}$

\section{Outcomes of perceived quality of nursing care}

From the patients' point of view, high quality nursing care leads to high dialysis adequecy, reduced burnout, increased satisfaction from the services, and ultimately improved quality of their life $18,22,24$

"Almost all dialysis patients lack good spirits. They've gotten physically and mentally weak, have become fed-up and lost hope in life. Some of them just die in a matter of hours." (Study 5) ${ }^{18}$

"I was afflicted with hepatitis here. I got it because the nurses don't follow hygienic procedures. They connect a patient to the machine while still using gloves stained by the blood of other patients. Where else could I have got hepatitis? I don't go to barbers or swimming pools. I am a victim of the nurses 'negligence and have paid huge bills to be treated for this so far." (Study 6) ${ }^{22}$

"The treatment I'm getting is pretty good so far", "its top-notch medical care", and "I received very good to excellent care." (Study 1$)^{24}$

Finally, the concept of patient perceived quality of nursing care from the perspective of patients was defined as "satisfaction from nursing care services and improvement of upgrading quality of life in an appropriate structure, including:Sufficient Human resource, qualitative and adequate equipment, financial support system, favorable physical conditions with using standard processes include: continuous monitoring of the syndrome, process of effective education to the patient, efficient care (general characteristics of the ward, such as the atmosphere between staff and attention to patient concerns), effective therapeutic relationships, participation and empowerment of the patient in the care process.

\section{Discussion}

This meta-center study was conducted with the purpose of clarifying the concept of perceived nursing care quality from the perspective of patients in hemodialysis ward. According to the best researchers' information, this is the first meta-analysis study of qualitative studies on the perceived nursing care quality in patients undergoing hemodialysis. The results of this study showed that the perceived nursing care quality from the perspective of patients consists of three main items of structure, process and outcome.

Appropriate structure of perceived nursing care quality from the perspective of patients: Sufficient Human resource, quality of equipment used, financial support of patients, and quality of patient care environment. In line with the results of the present study on Sufficient Human resource, accomplished studies have shown that sufficient human power number in different fields, especially nurses, plays an important role in providing high quality cares, especially that there is a greater shortage in terms of nurses number in the world. ${ }^{27}$ Nurses have the highest displacement among the health powers due to more shortage and inappropriate work environment. ${ }^{28}$ According to patients' opinion, quality of equipment is one of the key bases of the perceived nursing care quality from the perspective of patients. In line with the results of the present study, accomplished studies show that related professionals also believe that existing sufficient facilities have always direct relation to the provided care quality, especially in hemodialysis patients that much of the presented cares is provided through specialized devices. ${ }^{29}$ In line with the present study, which necessary to financial support has been raised as one of the major challenges among patients undergoing hemodialysis, qualitative study of Abma et al. have also shown that financial incentives cause to improve patient care. ${ }^{30}$ Hemodialysis, on the one hand, imposes high costs on the patient and the health sys- tem, and on the other hand, is accompanied with low outcomes of care quality indicators. ${ }^{31}$ The results of the Mushi et al. have shown that the global annual cost rate imposed for every hemodialysis patient in less developed countries is between Int $\$ 3,424$ and Int $\$ 42,785.32$ The proper environment is one of the important risk factors of nursing care quality. Studies have shown that the physical and psychological dimensions of the environment can help better improvement and adaptation of patients with the disease. The study by Prezerakos et al. has shown that work pressure, low resources, communication crises are the most important factors of high quality work environment. ${ }^{33}$ Dimensions of the process of perceived nursing care quality from perspective of the patients include continuous monitoring of the syndrome, effective patient education, efficient care, effective therapeutic relationship, and participation, empowering the patient in the care process. Continuous monitoring of the syndrome is an important component of daily cares of patients undergoing dialysis. In line with the present study, the Kidney Disease Improving Global Outcomes (KDIGO) guidline also emphasizes that the variety of dialysis different syndromes affects the quality of work and social life of patients. ${ }^{44}$ Also, the study Cabrera et al has shown that high burden of different syndromes causes poor outcomes in these patients. ${ }^{34}$ Studies show that supporting from families and patients using a problem-solving approach can help better and faster treatment of symptoms. ${ }^{34}$ Like other chronic diseases, effective therapeutic communication is one of the most important steps of establishing a correct treatment process. Some of the care challenges in the treatment of chronic diseases include patients undergoing hemodialysis, self-care behaviors such as fluid control, diet, correct medication use, participation in care, and acceptance of the patient's role. Reducing and managing these challenges requires correct education to the patient. ${ }^{35}$ Education to the patient is raised one of the fundamental principles of nursing care quality insofar as education to patient causes to reduce the complications and mortality of these patients. ${ }^{36}$

From the patients' point of view, high quality nursing care leads to high quality dialysis, reduced burnout, increased service satisfaction, and ultimately improved quality of their life. The accompanied studies are in line with the present study and shows a direct relationship of nursing care quality with high quality dialysis, ${ }^{37,38}$ increased satisfaction and quality of life in patients undergoing hemodialysis. ${ }^{39}$

The main strengths of this study were: 
according to the researchers' knowledge, this is the first study to evaluate the concept of perceived nursing care quality from the perspective of patients, standard approach has been used to perform different steps.

The most important limitations of the present study were: similar to other metasynthesis, the quality of their studies and interpretations is largely dependent on researchers. Only studies done in English and Farsi were searched. Included studies have been conducted only in a limited number of countries with specific cultures, so the generalization of study results are confronted with limitation and less can be generalizable to other communities.

\section{Conclusions}

The findings showed the importance of different aspects of the perceived nursing care quality from the perspective of the patients undergoing hemodialysis. The results of this study can help to a deeper understanding of the concept of nursing care quality and hearing patients' voice. Considering patients' opinions on the structural dimensions (adequate human power, effective equipment, desirable environmental conditions) and correct processes of service delivery (continuous monitoring of syndrome, training to the patient and effective communication) perceived nursing care quality by health policy-makers, and staff of dialysis ward can improves care quality and causes to enhance the quality of life of patients undergoing hemodialysis.

\section{References}

1. Hill NR, Fatoba ST, Oke JL, et al. Global prevalence of chronic kidney disease-a systematic review and metaanalysis. PloS One 2016;11:e0158765.

2. Bouya S, Balouchi A, Rafiemanesh H, Hesaraki M. Prevalence of Chronic Kidney Disease in Iranian General Population: A Meta-Analysis and Systematic Review. Therapeutic Apheresis Dial 2018;22:594-9.

3. Mills KT, Xu Y, Zhang W, et al. A systematic analysis of worldwide population-based data on the global burden of chronic kidney disease in 2010. Kidney Int 2015;88:950-7.

4. Stanifer JW, Muiru A, Jafar TH, Patel UD. Chronic kidney disease in low-and middle-income countries. Nephrol Dial Transplant 2016;31:868-74.

5. Grassmann A, Gioberge S, Moeller S, Brown G. ESRD patients in 2004: glob- al overview of patient numbers, treatment modalities and associated trends. Nephrol Dial Transplant 2005;20:258793.

6. Heidary Rouchi A, Mansournia MA, Aghighi M, Mahdavi-Mazdeh M. Survival probabilities of end stage renal disease patients on renal replacement therapy in Iran. Nephrol 2018;23:331-7.

7. Aljuaid MM, Alzahrani NN, Alshehri AA, et al. Complications of arteriovenous fistula in dialysis patients: Incidence and risk factors in Taif city, KSA. J Fam Med Prim Care 2020;9: 407.

8. Peeters MJ, van Zuilen AD, van den Brand JA, et al. Nurse practitioner care improves renal outcome in patients with CKD. J Am Soc Nephrol 2014;25:3908.

9. Epping-Jordan J, Pruitt S, Bengoa R, Wagner EH. Improving the quality of health care for chronic conditions. BMJ Quality Safety 2004;13:299-305.

10. Lohr KN. Medicare: a strategy for quality assurance: National Academies Press; 1990.

11. WHO. What is Quality of Care and why is it important? 2017. Available from: https://www.who.int/maternal_child_ad olescent/topics/quality-of-care/definition/en/

12. Donabedian A. Evaluating the quality of medical care. The Milbank Memorial Fund Quarterly 1966;44:166-206.

13. McGlynn EA, Asch SM, Adams J, et al. The quality of health care delivered to adults in the United States. N Engl J Med 2003;348:2635-45.

14. Edvardsson D, Watt E, Pearce F. Patient experiences of caring and person-centredness are associated with perceived nursing care quality. J Adv Nurs 2017;73:217-27.

15. Duffy JR, Hoskins LM. The quality-caring model $($ ): Blending dual paradigms. Adv Nurs Sci 2003;26:77-88.

16. Ponte PR, Conlin G, Conway JB, et al. Making patient-centered care come alive: achieving full integration of the patient's perspective. J Nurs Adm 2003;33:82-90.

17. Donabedian A. Exploratings in quality assessment and monitoring definition of quality and approaches to its assessment. Ann Arbor; 1980.

18. Nobahar M. Exploring experiences of the quality of nursing care among patients, nurses, caregivers and physicians in a haemodialysis department. J Ren Care 2017;43:50-9.

19. Vafaei AA, Nobahar M. The care preferences of patients under hemodialysis. $\mathrm{J}$ Renal Inj Prev 2017;6:210-5.
20. Lockwood C, Porrit K, Munn Z, et al. Chapter 2: Systematic reviews of qualitative evidence. Joanna Briggs Institute reviewer's manual The Joanna Briggs Institute; 2017.

21. Thomas J, Harden A. Methods for the thematic synthesis of qualitative research in systematic reviews. BMC 2008;8:45.

22. Hashemi MS, Irajpour A, Abazari P. Improving Quality of Care in Hemodialysis: a Content Analysis. J Caring Sci 2018;7:149-55.

23. Nobahar M, Tamadon MR. Barriers to and facilitators of care for hemodialysis patients; a qualitative study. J Renal Inj Prev 2016;5:39-44.

24. Rubin HR, Jenckes M, Fink NE, et al. Patient's view of dialysis care: Development of a taxonomy and rating of importance of different aspects of care. Am J Kidney Dis 1997;30:793801.

25. Wuerth DB, Finkelstein SH, Kliger AS, Finkelstein FO. Patient assessment of quality of care in a chronic peritoneal dialysis facility. Am J Kidney Dis 2000;35:638-43.

26. Rodrigues TA, Botti NCL. Providing and receiving nursing care during hemodialysis. Acta Paulista De Enfermagem 2009;22:528-30.

27. Baernholdt M, Mark BA. The nurse work environment, job satisfaction and turnover rates in rural and urban nursing units. J Nurs Manag 2009;17:994-1001.

28. Boyle DK, Miller PA. Focus on nursing turnover: A system-centered performance measure. Nurs Manag 2008;39:168.

29. Crews DC, Novick TK, eds. Achieving equity in dialysis care and outcomes: The role of policies. Seminars in Dialysis; 2020: Wiley Online Library.

30. Abma I, Jayanti A, Bayer S, et al. Perceptions and experiences of financial incentives: a qualitative study of dialysis care in England. BMJ Open 2014;4:e004249.

31. Saran R, Robinson B, Abbott KC, et al. US Renal Data System 2019 Annual Data Report: Epidemiology of Kidney Disease in the United States. American J Kidney Dis 2020;75:A6.

32. Mushi L, Marschall P, Fleßa S. The cost of dialysis in low and middle-income countries: a systematic review. BMC 2015; 15:506.

33. Prezerakos P, Galanis P, Moisoglou I. The work environment of haemodialysis nurses and its impact on patients' outcomes. Int $\mathrm{J}$ Nurs Pract 2015;21:132-40.

34. Cabrera VJ, Hansson J, Kliger AS, 
Finkelstein FO. Symptom management of the patient with CKD: the role of dialysis. Clin J Am Soc Nephrol 2017;12:687-93.

35. Alikari V, Tsironi M, Matziou V, et al. The impact of education on knowledge, adherence and quality of life among patients on haemodialysis. Quality Life Res 2019;28:73-83.

36. Alradaydeh MF, Khalil AA. The
Effectiveness of Physical Exercise on Psychological Status, and Sleep Quality among Jordanian Patients Undergoing Hemodialysis: Literature Review. Open J Nurs 2019;9:1267.

37. Karaboyas A, Morgenstern H, Li Y, et al. Estimating the Fraction of First-Year Hemodialysis Deaths Attributable to Potentially Modifiable Risk Factors: Results from the DOPPS. Clin
Epidemiol 2020;12:51.

38. Rezaiee O, Shahgholian N, Shahidi S. Assessment of hemodialysis adequacy and its relationship with individual and personal factors. Iranian J Nurs Midwif Res 2016;21:577.

39. Jung HM, Kim HY. A health-related quality of life model for patients undergoing haemodialysis. J Clin Nurs 2020;29:613-25. 